\title{
LAS RELACIONES DE SOLIDARIDAD Y RECIPROCIDAD EN LA PROTOHISTORIA FINAL EUROPEA
}

\section{SOLIDARITY AND RECIPROCITY RELATIONSHIPS IN FINAL PREHISTORY EUROPE}

\author{
JESÚS FRANCISCO TORRES MARTÍNEZ*
}

Lupus est homo homini, non homo, quom qualis sit non novit. (Lobo es el hombre para el hombre, y no hombre, cuando desconoce quién es el otro).

T. M. Plauto (Asinaria v. 495).

\begin{abstract}
Resumen: Las relaciones de reciprocidad son un elemento fundamental para comprender las sociedades de la Protohistoria Final, especialmente en el ámbito indoeuropeo de la península ibérica y en general, en Europa central y meridional. En este artículo se presenta una introducción teórica general sobre el tema y un estudio de la reciprocidad y las relaciones de solidaridad en las sociedades de la Protohistoria Final. La estructura económica y los modos de explotación del medio de estas culturas agro-ganaderas tienen en las relaciones de reciprocidad un modo fundamental de construcción y organización de los distintos grupos sociales. Las amplias redes de relación que a partir de este concepto se construyen dibujan culturas con un fuerte componente guerrero, organizadas en estructuras vecinales y linajes con grupos familiares amplios organizados por grupos de edad. Esta estructura forma extensas cadenas de solidaridad que desembocarán en la construcción de grandes grupos étnicos.

Palabras Clave: Bronce Final, Edad del Hierro, estructuras sociales, relaciones sociales.
\end{abstract}

Abstract: Reciprocity relationships are a fundamental element which helps us understand Final Protohistory societies, especially in the sphere of the Iberian Peninsula and, generally, of Southern and Central Europe. This article comes out as a theoretical and general introduction to the subject, and a study of reciprocity and solidarity relationships in Later Prehistory societies. Reciprocity relationships work as an essential way of construction an organization of different social groups, in the economical structure and ways of exploitation of the resources of these cultures, related to both agriculture and livestock. Wide relationship networks built upon this concept draw cultures which have an important warlike compound, organized as neighboring structures and lineages with familiar groups organized by groups of age. This structure creates extensive solidarity chains that will lead to the construction of big ethnic groups.

Key words: Late Bronze Age, Iron Age, social structure, social relationship.

(IMBEAC). Correo-e: ketxutorres@yahoo.com; http://ucm.academia.edu/JesusFranciscoKechuTorresMartínez, http://www.imbeac. com/ http://www.montebernorio.com/ 


\section{INTRODUCCIÓN: LA RECIPROCIDAD Y LAS RELACIONES SOLIDARIAS COMO ELEMENTO FUNDAMENTAL DE LA CONSTRUCCIÓN DE LAS SOCIEDADES HUMANAS}

Una parte del discurso histórico actual parece intentar establecer que la sociedad humana se desarrolla como una pugna continua. Las relaciones entre humanos se basan principalmente en el egoísmo, son interesadas y calculan siempre las contraprestaciones de los actos y los gestos. En este modelo social solo a través de la coerción y la violencia se impone el liderazgo y este es siempre de los más fuertes. Detentar el poder tiene como fin apropiarse de una parte importante del sustento y los bienes de los demás miembros del grupo y empobrecerlos para, de este modo, poder dominarlos. Las cualidades humanas (intelectuales, afectivas, empáticas) de los líderes parecen no tener importancia. El poder se ejerce a través de la coerción y el miedo y la mayoría de las sociedades son víctimas resignadas de ese principio humano universal.

Una gran parte de este discurso en la mayor parte de las ocasiones no es explícito y aparece como una verdadera prenoción, o una preconcepción, en la manera en que E. Durkheim (2005: 147-174) formuló este concepto. Se basa en las tesis desarrolladas en el siglo XIX a partir del Darwinismo. En parte provienen y se basan en principios de la doctrina darwinista y de otros autores como T. Malthus o H. Spencer para desarrollar lo que se ha denominado Darwinismo Social: en un mundo de recursos limitados los humanos luchan entre sí y el éxito es de los individuos más fuertes. Estos perpetúan sus aptitudes, actitudes y genes "triunfadores", que deben imponerse a otros más débiles que no tienen tanta capacidad para sobrevivir. De otro lado está la necesidad, por parte de determinadas ideologías, de trasladar los conflictos de las sociedades contemporáneas al pasado como medio de legitimar sus intereses y puntos de vista sobre la sociedad humana en general (Lewontin et al. 1996, Sandin 2000, Espina 2005, Goleman 2010a: 203-223).

Sin embargo, los humanos somos seres sociales, mamíferos gregarios, forman grupos familiares y suprafamiliares con los que interactúan de distintos modos con el medio para obtener los recursos necesarios para sobrevivir. En este sentido, la Historia nos muestra culturas humanas, sociedades y grupos, que se adaptan al medio y sobreviven, no individuos. La idea de individuos aislados intentando sobrevivir es esencialmente absurda y falaz. Es precisamente la solidaridad uno de los elementos fundamentales que han permitido la supervivencia y el desarrollo de la especie humana. Esto, que debería resultar evidente, sigue siendo en muchos casos una realidad marginada de la investigación de la Prehistoria. Por ello, es necesario reivindicar no solo el papel de la solidaridad y la reciprocidad en el desarrollo de la especie humana sino también las nuevas evidencias que refuerzan el papel esencial de este tipo de prácticas.

Las últimas investigaciones en Neurociencia apoyan el papel de la solidaridad en la construcción de las sociedades humanas. Este tipo de comportamiento vendría establecido en los modos de funcionamiento cerebral de los humanos, pero es patrimonio también de los primates. Esto no quiere decir que los primates y los humanos recurran tan solo a la solidaridad y no desarrollen comportamientos violentos en sus relaciones, sino que los comportamientos solidarios tienen un componente casi biológico, que los establecen como la primera opción en las relaciones sociales. Y esto incluye también comportamientos como la abnegación o el sacrificio incluso ante individuos desconocidos. Estas pautas de comportamiento son intrínsecas al género Homo (Goleman 2010b: 331-349, 2010b: 26-43, 58-91, 467-471).

El afecto forma una parte muy importante de las relaciones humanas, es subjetivo y no está sujeto a racionalizaciones. En este contexto, resulta fundamental estudiar la historia del papel de la afectividad y lo emocional en las relaciones humanas. No obstante, la Historia es el estudio racional y objetivo de las sociedades y las relaciones sociales en el pasado, pero estas relaciones no tienen por qué ser racionales o comportarse de un modo racional (Chic 2009: 13-14, 19-20, 56, Hernando 2002: 7-46, Goleman 2010b: 35-70, 432442, 2010b: 259-288). Recientes estudios han revelado (empíricamente) algo que, intuitivamente y por "sentido común", se sabe desde hace mucho tiempo: que la inteligencia emocional es fundamental en las relaciones humanas.

La inteligencia emocional no es la capacidad de una persona para engañar a los demás sobre afectos que no siente sino la capacidad para sentir, empatizar y generar afecto de forma sincera en los demás. Las relaciones entre humanos son emocionales y, por tanto, no tienen por qué resultar lógicas. Es más, cuando una persona establece con otras personas relaciones solamente lógicas y racionales o bien interesadas, egoístas y despóticas, recibe el rechazo social y se le tilda de "interesado" cuando no de "monstruo". La inteligencia emocional sirve para construir redes sociales de 
colaboración y reciprocidad amplias y también forma una parte esencial y muy importante de cuestiones tan relevantes como el liderazgo (Chic 2009: 19-20, Goleman 2010b: 73-93, 167-208, 2010b: 163-184, 289-297, 312-316, 482).

Dentro de las relaciones humanas, la generación y preservación del afecto son muy importantes. Uno de los mecanismos de preservación del afecto y las buenas relaciones entre personas y grupos (aquellas que son equilibradas y que resultan positivas para todas las partes) es la reciprocidad. Esto es especialmente marcado en las relaciones de tipo económico, elemento esencial en la construcción de las redes sociales, tanto familiares como suprafamiliares (Chic 2009: 19-20, 41-42, 5962 ). La reciprocidad ha sido una parte fundamental en la construcción de las redes sociales a lo largo de la historia del género Homo. Esa pauta no ha cambiado esencialmente durante milenios, incluso con el surgimiento de las sociedades complejas, hasta el momento actual. Las formas más básicas y extendidas de reciprocidad, la solidaridad (mutua colaboración y apoyo, reparto e intercambio igualitario de bienes y servicios) y la comensalidad (compartir el alimento) son elementos esenciales en la construcción de las redes de tipo familiar y suprafamiliar ya que son la antesala de la construcción de formas de apego y afecto. Tanto la solidaridad como la comensalidad se basan en la capacidad para sentir y generar empatía y en el afán por mantener esta pauta de comportamiento, que genera sentimientos de afecto y vinculación entre los humanos (Chic 2009: 145-153, Goleman 2010b: 167-208, 2010b: 1525, 372-384, 419-430, 442-449).

Tanto las formas conocidas de intercambio de bienes como las formas de relación a través del intercambio en las sociedades premodernas han sido una de las cuestiones más debatidas en el estudio histórico de la Prehistoria y la Antigüedad. La necesidad de elementos empíricos para desarrollar este tipo de discusión de un modo científico ha hecho que la mayoría de los datos manejados procedan de informaciones de tipo antropológico.

La Antropología ha desarrollado la Antropología Económica como ámbito de investigación de lo económico en las sociedades humanas, pero este conocimiento sólo es útil en parte a la Historia y a la Arqueología (Moreno 2011: 145-156, 161-170). En muchos casos estas informaciones provienen de sociedades muy alejadas geográfica y culturalmente (y en el tiempo) de las culturas de la Protohistoria europea, pero poseen lo que se denomina un "valor sociológico general" (Mauss 1971: 223-224).
La obra de referencia sigue siendo el Ensayo sobre el Don (Gift) de M. Mauss $(1971,2010)$ publicada en 1924 (Sahlins 1983: 167-202, Giobellina 2010, Moreno 2011: 113-124). En esta obra se recoge ya el carácter universal de las relaciones de reciprocidad y de las leyes que rigen cuestiones como la generosidad y el intercambio. Dar, recibir y devolver son las bases de la convivencia entre los grupos humanos. Y no sólo entre estos, también entre los humanos, los dioses y otros seres de naturaleza espiritual. Con posterioridad, la obra de K. Polanyi (1987), aunque referida en principio al auge de la economía capitalista y de mercado, sirvió para remarcar la gran diferencia cultural existente entre las sociedades premodernas o precapitalistas y las actuales, diferencia que ya había sido señalada por M. Mauss (2010: 70-73). Uno de los fenómenos más importantes es que en las sociedades premodernas y otras sociedades precapitalistas (o mejor, no integradas en el capitalismo o que funcionan con mecanismos socioeconómicos anteriores al capitalismo) los procesos económicos están embebidos o imbricados (embedded) en el resto de las instituciones sociales y resultan inseparables. De este modo, todo lo social tiene una dimensión económica y todo lo económico tiene una dimensión social, como ya había explicado M. Mauss (Moreno 2011: 124-134). Este concepto es muy importante para la comprensión de determinados fenómenos de larga duración histórica económico-culturales y de la preservación, en las economías agro-ganaderas tradicionales, de formas de relación (económicas) que resultan propias de momentos anteriores a la instalación del capitalismo y su sistema de valores. La obra de M. Sahlins (1983) sobre Economía Prehistórica aportó nuevos elementos a esta discusión (Moreno 2011: 156). Recientemente, otros autores y obras han contribuido a la discusión científica en el ámbito de la Arqueología, entre los que destacan especialmente los trabajos de M. Godelier (1999), M. Osteed (2002) o K. Sykes (2005).

Una de las obras más sugerentes de las que han tratado el tema de la reciprocidad es la de A. Hernando (2002). En ella se tratan cuestiones como la cultura, las identidades, las relaciones sociales y la reciprocidad. Es más, para esta autora uno de los elementos que caracteriza a las sociedades es el de la reciprocidad y su grado de complejidad cultural se establece en relación con el tipo de relaciones de reciprocidad que establecen. La complejidad de las sociedades a través del tiempo está caracterizada también por sus formas de relacionarse (entre sí, con otros humanos y con la naturaleza y el mundo) y las relaciones de reciprocidad son uno de los elementos esenciales. En este sentido, 
son muy importantes también los cambios profundos de mentalidad, así como de modos de pensamiento y de relación con el mundo que se dan en las distintas sociedades en su transformación paulatina a través del tiempo. Sin embargo, las consideraciones sobre el surgimiento de la desigualdad social o las fases de evolución socioeconómica de las sociedades, según los dogmas del Marxismo, limitan enormemente el desarrollo general de sus enunciados.

El papel de la antropología en los estudios sobre la reciprocidad en la Historia es más que importante, esencial. Personalmente, considero que las analogías entre sociedades demasiado alejadas en el tiempo y el espacio en muchas ocasiones resultan difíciles de admitir como válidas, porque ocupan espacios geográficos y nichos ecológicos con condiciones ambientales muy diferentes y con niveles de desarrollo tecnológico y social muy distintos. Resulta imposible establecer la necesaria proximidad cultural y tampoco es posible establecer la filogénesis entre la práctica documentada y la sociedad del pasado en estudio. Esto puede evitarse cuando resulta posible realizar trabajo etnoarqueológico y etnohistórico sobre sociedades con las que es posible establecer lazos de tipo filogenético: continuidad contrastable históricamente en la ocupación del mismo espacio geográfico-ambiental. Si no es posible establecer esta continuidad (nos estamos refiriendo a sociedades agro-ganaderas y, por tanto, territoriales), será siempre recomendable buscar sociedades que sean lo más similares entre sí en los aspectos que hemos marcado como necesarios. De otro modo estaremos buscando un dato que soporte una opinión, no aportando verdaderas evidencias y se ha usado y abusado de este tipo de "evidencias". Así resulta normal buscar ejemplos que refuercen lo que se opina, aunque sea en sociedades que difícilmente soportan una comparación. Por ejemplo, analogías entre sociedades africanas actuales y sociedades de la Edad del Hierro europeas, cuando en la mayoría de los casos la distancia geográfica, ambiental, tecnológica, de desarrollo social y cultural es insalvable.

No obstante, hemos de remarcar que resulta evidente que existen comportamientos y tendencias que aparecen como universales, sujetos a lo que podemos denominar como "patrones de especie".

Así pues, podemos decir que la reciprocidad es la norma que rige las relaciones en las sociedades primitivas, premodernas o preindustriales. Las relaciones tienden a autorregularse por mecanismos de control que garantizan que dicha reciprocidad sea equitativa, más en un aspecto cualitativo que cuantitativo, aunque ambos aspectos son importantes. Sin embargo en general, cuanto más próximas (más cargadas de afecto) son las relaciones entre los humanos más tienden los sistemas de intercambio a la reciprocidad y, cuanto más lejanas, menos recíprocos son estos (Sahlins 1983: 214, Hernando 2002: 119-214, Torres-Martínez 2011a: 253-260).

Esta forma de relacionarse afecta a los intercambios con el resto de los humanos y funciona de modo diferente según el grado de proximidad, dependiendo si el parentesco es más próximo o más lejano, y funciona también de modo distinto con los nofamiliares y los que no están incluidos en las redes de la parentela (Sahlins 1983: 214-223). Las relaciones de reciprocidad construyen una comunidad con sus propias normas e intereses comunes que establece quién está dentro de ese ámbito de relación y quién no lo está. Esto construye las redes de relación vecinal (en el caso de los nofamiliares) y determina quién está fuera, quién es el extraño, el otro y este hecho es tan importante, que resulta inseparable de la concepción religiosa y moral de la existencia y del sentido del honor (propio y ajeno). Pero además, afecta a los intercambios que se realizan con los espíritus y los dioses, a los que se agradece que compartan sus recursos con los humanos (la naturaleza es propiedad de los dioses y los humanos forman parte de la naturaleza), integrándolos en sus redes de reciprocidad y comensalidad (Mauss 1971: 173, 178, 195, 199-200, 202, 222, Chic 2009: 62-64). Establecen lo que es justo, correcto y apropiado en las relaciones entre humanos y los seres del más allá, no solo en las relaciones que podemos establecer como económicas (comensalidad, ayuda y asistencia mutua, hospitalidad, etc.), sino también en general en todas las situaciones $\mathrm{y}$ en todos los tipos de comportamientos. Todos deben ser respetados y deben obtener algo a cambio de algo, incluidas cuestiones tan inmateriales como el afecto, el respeto o la dignidad (Torres-Martínez 2011a: 253-258, 443-444, 479-487).

Por todo esto, es importante replantearse nuestra visión de la sociedad humana, de cómo se construye esta y de cómo se establecen los ámbitos de relación social a escala micro, meso y macro. Debemos replantearnos cómo se construyen las jerarquías sociales, cómo consiguen la necesaria legitimidad, el apoyo y el consenso social y cómo consiguen mantenerse.

La pirámide social es una construcción desde abajo, no desde arriba. Las sociedades se construyen sobre la seguridad y la fe en los valores y en la mutua confianza que sus integrantes comparten (Chic 2009: 41-43, 65, Hernando 2002: 49-63, 119-164). Por esto debemos 
insistir que es sobre la base de la solidaridad y la reciprocidad sobre la que se construyen todas las demás estructuras y modos de relación social. Es este no solo un fenómeno de tipo histórico con una duración determinada o un fenómeno de larga duración histórica que se prolonga varios siglos (Braudel 2002: 147-177) sino que podemos afirmar que se trata de un comportamiento intrínseco en nuestra especie, entre los miembros del género Homo.

Esto no implica que no exista la violencia o la injusticia entre los humanos ya que estos comportamientos forman parte también de nuestro comportamiento de especie y se expresa de modo organizado, sistemático y tremendamente cruel en los conflictos entre distintos grupos. En las sociedades premodernas, la violencia hacia el interior de los grupos puede considerarse como un fenómeno normalmente puntual, aunque real, complejo y dramático.

El cambio fundamental en las sociedades humanas parece producirse en el momento en que estas pasan de ser sociedades de cazadores-recolectores a sociedades productoras o agro-ganaderas de tendencia sedentaria y territorialidad excluyente. En este caso, las sociedades transforman los mecanismos de reciprocidad generalizada, propios de los grupos cazadores recolectores, en otros de tipo más excluyente, con mecanismos de reciprocidad positiva al interior y negativa al exterior (Hernando 2002: 119-164, TorresMartínez 2011a: 13-14).

Por su parte, en las sociedades agro-ganaderas, las redes de reciprocidad, familiares y también vecinales están íntimamente relacionadas con la territorialidad. Esta se construye a través de la explotación de los recursos de un territorio y la economía tiene aquí una enorme importancia (Torres-Martínez 2010). Esto implica que las redes de relación social familiar y suprafamiliar se establecen dentro de las coordenadas geográficas y ambientales del ecosistema o ecosistemas que una sociedad explota (Dyson-Hudson y Smith 1983: 151-160). De este modo, no son iguales las relaciones con aquellos individuos o grupos con los que se explota y defiende un territorio que con los potenciales competidores. En la competencia con otros grupos por territorios que se consideran necesarios o recursos que resultan escasos, los humanos siempre hemos sido capaces de desplegar una enorme ferocidad. Los efectos de esta los multiplica nuestra inteligencia y nuestra sociabilidad (integradora hacia adentro y excluyente hacia afuera), aunque este tipo de comportamientos no son considerados como habituales o prioritarios, por mucho que sean relativamente frecuentes en la Historia (Sahlins 1983: 219). En todo caso, los elementos clave en estos procesos son los cambios que se producen en los valores del grupo en las relaciones "con los otros", que pasan de ser "vecinos" o "próximos" a "enemigos". Los valores y las normas se flexibilizan y se convierten en elementos meramente relativos y situacionales. Pero, al mismo tiempo, hacia el interior de las sociedades, estos conflictos refuerzan las prácticas de solidaridad y los mecanismos de reciprocidad, lo que hace que la cohesión interna del grupo se intensifique (Sahlins 1983: 218, 234-235).

\section{FORMAS DE RECIPROCIDAD "POSITIVAS" EN LAS SOCIEDADES CÉLTICAS DE LA PROTOHISTORIA FINAL EN IBERIA}

En sociedades esencialmente agro-ganaderas y territoriales, como es el caso de las sociedades célticas que trataremos, la relación social se produce principalmente en el ámbito familiar y suprafamiliar, o "vecinal". Esto genera una tendencia a las relaciones de reciprocidad positiva hacia el interior de la sociedad y negativa hacia el exterior, acentuada además en muchos aspectos por el carácter guerrero de esta cultura (Hernando 2002: 115). La reciprocidad afecta a todo tipo de relaciones, tanto en la paz como en la guerra, y las culturas guerreras la integran también dentro de sus prácticas esenciales. En la Protohistoria, el desarrollo de las redes de relación vecinal (basadas también, y sobre todo, en la reciprocidad) ampliaron el alcance, la intensidad y la complejidad de estas formas de relación creando nuevas fórmulas. De este modo, estos nuevos sistemas de reciprocidad crearon redes y estructuras de interdependencia, que son la base de los nuevos sistemas sociales. Estas sociedades creaban lo que se ha denominado fondos ceremoniales para hacer frente a este tipo de intercambios, lo que ha sobrevivido en las sociedades campesinas tradicionales (Wolf 1975: 16-18).

El intercambio se realiza siempre desde la premisa de la generosidad como base de la reciprocidad. El regalo o Don que se hace se convierte en una inversión dentro de un fondo infinito de deudas entre individuos, familias y linajes. Estas deudas de gratitud alcanzan también a las relaciones entre los humanos y los antepasados, los espíritus y los dioses. Las formas de relación están basadas en la generosidad ya que, llegado el caso, los demás serán tan generosos con nosotros como nosotros lo seamos con ellos. Por este motivo, 
la reciprocidad y la generosidad son no solo obligadas, sino también, en gran medida, indiscriminadas. Se busca establecer y mantener amistades por medio de obsequios, de bienes materiales y de objetos hermosos (Coldstream 1983). M. Sahlins (1983: 204) explica así esta idea «Si los amigos hacen regalos, son los regalos quienes hacen amigos. Esta función instrumental es la función decisiva de una gran parte del intercambio primitivo»...«la corriente material garantiza o inicia las relaciones sociales». Pero no solo son los regalos los que establecen relaciones de reciprocidad, también lo hacen los servicios que se prestan.

Los favores, ayudas o apoyos, que se prestan e intercambian fundamentalmente entre vecinos, son servicios de difícil cuantificación por cuanto en muchos casos resultan esenciales para la supervivencia de la familia o el grupo. De este modo, se establecen relaciones de reciprocidad de servicios por servicios y de servicios por bienes. Esta lógica es también la que ha pervivido básicamente en las relaciones de reciprocidad que se han mantenido en la sociedad campesina tradicional, al menos en el área cantábrica, como hemos podido recoger en la bibliografía etnográfica y también en el trabajo de campo etnoarqueológico (Cabal 1992: 15-17, Fernández et al. 2002: 15, Valdés y Lorenzi 2004, Torres-Martínez 2011a: 15-17, 254-256).

En las sociedades de tecnologías simples de tipo campesino, en las sociedades de la Antigüedad o en la sociedad campesina tradicional, la solidaridad y las prácticas de reciprocidad son esenciales para garantizar la cohesión y la supervivencia de los grupos humanos (Torres-Martínez 2011a: 13-14). Las relaciones de amistad, expresadas a través de la solidaridad, reciprocidad y hospitalidad, tenían una enorme importancia en las sociedades protohistóricas y, en general, en todas las sociedades de la Antigüedad (Herman 1987: 10-72). Esta importancia ha subsistido en Europa hasta la actualidad, especialmente en la sociedad tradicional campesina. Esto es debido a que la vida humana no ha sido posible a medio o largo plazo sin una estrecha colaboración entre todos aquellos que viven juntos o próximos, sean estos familiares (relaciones gentilicias) o vecinos (relaciones suprafamiliares o vecinales).

Las relaciones de solidaridad, reciprocidad y hospitalidad tenían una enorme importancia en las sociedades protohistóricas y, en general, en todas las de la Antigüedad. En el caso del ámbito cultural céltico de la Edad del Hierro, el funcionamiento social de estos grupos no puede ser entendido sin comprender la enorme importancia que tenía la práctica de la solidaridad y reciprocidad. En este sentido podemos enumerar una lista de distintos tipos de relaciones de reciprocidad, tanto positivas como negativas:

en la familia.

con la parentela.

con los vecinos.

con los miembros de la comunidad.

dentro de la propia etnia.

con los antepasados.

en las relaciones con el más allá y los dioses.

con los extranjeros y desconocidos.

con los enemigos.

Como podemos apreciar, las relaciones de reciprocidad construyen las comunidades desde la misma base social y sirven para entretejer complejas redes de interacción e interdependencia en mecanismos que son en realidad, fenómenos de larga duración histórica. Todos deben favores y ayuda a todos de modo continuo. Los favores realizados y los dones dados se convierten en una garantía de ayuda y asistencia cuando esta llega a ser necesaria y, muy especialmente, en momentos adversos. Por eso, las redes de reciprocidad sobrepasan el tiempo y el espacio, proyectándose también hacia otras esferas de relación. Las relaciones de reciprocidad se desarrollan también con los antepasados, ya que las generaciones de un momento dado, en muchos sentidos, deben mucho de su bienestar a los que les precedieron en el tiempo y trabajaron duro, corrieron riesgos o afrontaron guerras para garantizar el territorio y los recursos a sus descendientes. Del mismo modo, los mortales deben tener buenas relaciones con los dioses ya que son ellos, en última instancia, los que permiten la vida de los hombres y pueden hacer que estos sean prósperos y felices o pobres y desdichados. También es imprescindible ser generosos con los desconocidos y extranjeros, dándoles hospitalidad, la misma que esperamos si hemos de viajar. Incluso con los enemigos, es necesario respetar unas reglas no rebasando unos límites siempre en negociación a través de la reciprocidad en el comportamiento de unos y otros.

\subsection{Reequilibrio}

Como hemos explicado, en la totalidad de las sociedades premodernas conocidas, el mantenimiento del equilibrio social está basado en la reciprocidad. De este modo, esta práctica se convierte en un garante que limita la desigualdad entre los miembros de una misma sociedad. Este tipo de mecanismos intenta evitar que 
haya un exceso de acumulación de bienes o de recursos o que alguien se beneficie en exceso de favores y servicios. De este modo, se garantiza que todos los integrantes de la sociedad tengan una relativa "igualdad de oportunidades". Pero eso no hace iguales a todas las partes, de modo que tanto los distintos individuos como las familias y las parentelas no son iguales. La inteligencia, el talento, la destreza social, el carisma o el valor no son características que todos los individuos poseen en igual proporción ni tampoco se da equitativamente en las distintas familias. Así mismo, los dioses parecen repartir suerte y fortuna de modo aparentemente caprichoso. De este modo, aunque la reciprocidad (y otros mecanismos de redistribución) establezca un marco de relación tendente al igualitarismo, la realidad es que ni los individuos ni las familias son iguales. Este tipo de fenómenos está presente en realidad en la práctica totalidad de las sociedades conocidas (Sahlins 1983: 84-89, Chic 2009: 148-149).

En la épica de las culturas antiguas, los relatos funcionan como mecanismos de transmisión de valores sociales positivos ya sean afectivo-emotivos como racionales. En el caso concreto de la sociedad reflejada en la Ilíada, M.Y. Montes (2006a, 2006b) recoge la equivalencia que existe entre el concepto de orden social y el de equilibrio social. Además, según este autor, se constata la existencia de un miedo al desorden que se conjura a través de estrategias de recuperación del equilibrio social. En este sentido, las relaciones sociales deben ser siempre del todo previsibles, ajustadas a las normas aceptadas por todos de un modo cuasi religioso, y la búsqueda en esas relaciones de un equilibrio apropiado es continua. Puede que los individuos y las familias no sean iguales pero deben comportarse de acuerdo a unas normas.

Esto resulta especialmente manifiesto en el comportamiento entre los aristoi, a los que podemos definir como "los otros iguales". Estos serían aquellos a los que uno considera próximos y afines ya que reúnen lo que se considera que son las mejores cualidades, las que la sociedad considera como positivas. Esto determina el modo en el que uno quiere ser y, por tanto, en cómo se comporta. No resulta extrapolable a conceptos actuales de entender las relaciones sociales como el de la "clase social". En este sistema, el que consigue ser admirado por sus cualidades y comportamiento (interiorización del arquetipo) sirve como modelo social. Se convierte así en un representante de los ideales de esa sociedad, que se quiere ver reflejada en las características encarnadas por esa persona. El conjunto de estas cualidades, que son vividas y exhibidas, hacen que se le considere como a un "principal". Todos los individuos aspiran a ser considerados así y todas las familias quieren ser tratadas como destacadas, principales. Pero no todos los individuos pueden llegar a destacar, ni todas las familias reúnen el suficiente prestigio social como para ser así consideradas (van Wees 1992: 222228, Finley 1999: 131-172).

Entre los mejores representantes de los valores de una sociedad (los que destacan, los principales) y a los que se considera próximos, hallamos a los denominados philotes (filotes), entre los que se establecen varios tipos de relaciones. Están aquellos con los que se establecen relaciones de tipo parental (a través del parentesco) y aquellos a los que se trata como si fueran parientes sin que lo sean realmente. En todo caso, se aplican relaciones de reciprocidad y solidaridad que se intenta que sean lo más estrechas posible, como si se desarrollaran entre parientes. No se esperan agresiones, ni reacciones violentas y se establece la

ayuda, colaboración, rescate, consejo, preocupación, reciprocidad, generosidad... Esa retórica de la philotes nace y se define en las relaciones de alteridad de tipo parental, parangón de todas las relaciones interpersonales, de ahí "es exportada" a las de alteridad no parental, principalmente entre "hetairoi" y asimismo a la que hemos llamado "filotes cultural" y que incluye "orkia" (acuerdos) "zsenia" (amistad hospitalidad) e "iketia" (súplica) (Montes 2006b: 122).

Para garantizar un comportamiento adecuado está la aidos o "vergüenza social" ante cualquier comportamiento inadecuado y la eleos, "compasión" o "acción solidaria" hacia el aristos desconocido o extranjero, lo que incluye la práctica de la hospitalidad, sobre lo que volveremos más adelante (Montes 2006a: 38-116, 2006b: 122).

En caso de producirse cualquier tipo de desorden (un conflicto o una ruptura) resulta imprescindible la rápida recuperación del orden social por medio del areskó (reequilibrio). Esta se produce a través de una compensación tanto a través de palabras y gestos como de la entrega o intercambio de bienes, que permitan reequilibrar una situación que resulta indeseable, de modo que «el conocimiento y respeto por las normas del reequilibrio permiten mantener el orden social» (Montes 2006b: 132). Así, en la Ilíada la recuperación de unas buenas relaciones sociales aparece como una preocupación continua (Montes 2006: 110-116, 2006b: 126-140).

Este tipo de valores y comportamientos no son exclusivos de los "principales" sino que estos los deben asumir de modo ejemplar como máximos exponentes 
de los valores colectivos. No obstante, son los principios del conjunto de la sociedad y a los que esta aspira como ideales (Chic 2009: 64-65). Es, por tanto, el prestigio un elemento esencial en una comunidad en la que las relaciones personales y familiares están sujetas a estos mecanismos de reciprocidad y reequilibrio continuo. Es esta búsqueda del equilibrio en las relaciones lo que explica la cohesión interna de unas sociedades segmentarias con una lógica social muy alejada de las actuales. En este sentido, debemos resaltar la importancia del honor, cuestión que atañe a todos los integrantes de la sociedad (y no solo a los dirigentes) y que implica especialmente a las familias, como garante de ese mecanismo en continuo reequilibrio dentro de ese sistema de deudas morales. Deudas que no se pueden demorar ni olvidar y en las que el titubeo a la hora de reintegrar un don, un servicio o una ofensa genera una profunda vergüenza que se hace colectiva. M.Y. Montes (2006a: 116) afirma: «...en la solución de las disputas en Homero hay dos principios generales, por un lado el de la adherencia a las normas de comportamiento adecuado y por otro el de la compensación por los daños (restitución, retribución o ambas)». Es un sistema de valores en el que el incumplimiento de lo que exige el honor resulta impensable (Montes 2006b: 122, Verger 2009: 66-70).

\section{LA RECIPROCIDAD Y LAS RELACIONES VECINALES EN LA CONSTRUCCIÓN Y ARTICULACIÓN DE LAS ESTRUCTURAS SOCIOPOLÍTICAS}

Los ejemplos mencionados anteriormente pueden servir para ilustrar los comportamientos sociales que existirían en las culturas de tipo céltico del norte de la península ibérica. Estos mecanismos de relación social se sitúan, en primer lugar, en la base de las relaciones humanas de supervivencia y subsistencia y son fáciles de percibir a través del estudio de las distintas actividades económicas y de la articulación del territorio. Sin embargo, van mucho más allá de estas ya que través de ellas se construyen, como veremos, las demás estructuras sociales (Torres-Martínez 2003, 2005, 2011a: 65-260). Este hecho se debe a que este tipo de conductas son las que sirven como marco que permite establecer y construir las redes de relaciones vecinales. Estas, a su vez, son aquellas desde las que se establecen las formas de relación y gobierno de tipo suprafamilar como son los pagi o las civitates e incluso las etnias en sociedades de tendencia fragmentaria como estas (Torres-Martínez 2011a: 365-383). Este tipo de tendencias sociales se mantendrán, en gran medida, en la sociedad tradicional campesina.

En el occidente y centro de Europa, en el final de la Edad del Hierro asistimos al desarrollo de sociedades definidas como de tipo protoestatal, aunque personalmente creo que se trata más bien de sociedades estatales en un modelo distinto (agro-ganadero, guerrero y de tipo segmentario) al que es conocido en el ámbito mediterráneo. En todo caso, este tipo de estructura social supone el máximo desarrollo de lo que hemos definido como un modelo de estructura vecinal. Este tipo de ámbitos de relación y de estructuración social y territorial debió surgir con la aparición de núcleos protourbanos (aldeas y poblados), dentro de territorios que estaban ya densamente ocupados y con una intensa explotación económica.

Las relaciones vecinales establecen unas normas que permiten una convivencia pacífica y una explotación ordenada del medio y sus recursos que, en muchos casos, ha de realizarse de modo conjunto y cooperativo entre grupos no unidos por el parentesco. Este tipo de relaciones, perfectamente estructuradas y regladas por la tradición, se basan en la práctica de la reciprocidad entre vecinos. Este tipo de estructura de relación económica y social intensificó su desarrollo y su institucionalización con la aparición de una sociedad campesina y guerrera. Mientras que los castros y oppida (pagus/ civitas/populus) son los elementos vertebradores de la estructura político-territorial. Su institución más característica era la asamblea, institución que representaba la culminación de la estructura de relaciones vecinales, donde los habitantes de un mismo territorio tomaban decisiones y celebraban cultos religiosos conjuntos (Almagro 2002: 64, Brunaux 2004: 17-18).

El autor griego Estrabón (III, 3, 7), en un célebre pasaje sobre los pueblos del cantábrico, describe una de estas "asambleas", como una celebración comunal en la que se desarrollaban rituales religiosos, reuniones políticas y maniobras de tipo "militar", que comprendían probablemente a toda una etnia. Este tipo de celebraciones colectivas serían uno de los elementos fundamentales para el reforzamiento de los lazos de solidaridad social y de la identidad colectiva (García et al. 2003, Gómez 2007: 217, nota 39 y 219, Alberro 2006, García y Santos 2008: 128-131, Torres-Martínez 2011: 320-321, 377-378, 480-487).

La arqueología está aportando cada vez más evidencias sobre este tipo de celebraciones en distintas áreas de la península ibérica (Álvarez 1993: 272-279, Marco 1993: 496, Ruiz y Álvarez 1999, San Miguel 1995: 373-374, 
Torres-Martínez 2005: 318-319). Así, el yacimiento de Gastiburu (Arratzu, Bizkaia), publicado por L. Valdés, es interpretado como un lugar para celebraciones de asamblea y para rituales religiosos (Valdés 2006, 2009a, 2009b, Valdés y Pujana 2003). La celebración de asambleas en otras partes de Europa central y occidental ha sido también tratada por distintos autores europeos como S. Fichtl (2005: 145-149, 2012: 121-124), Ch. Peyre (1996: 6-8) o S. Verger (2009: 63-64). M. Fernández (2011a: 12-14, 2011b) ha publicado recientemente una visión de conjunto sobre este tipo de celebraciones y su significado.

La asamblea, con el ritual religioso, el banquete y la fiesta tienen mucho de sistema de intercambio equilibrado de bienes tanto en los sistemas de reciprocidad familiar como vecinal. En estas ocasiones se ofrece a los demás todo tipo de alimentos especiales y se recibe un trato similar. Es habitual que se dediquen a este tipo de fiestas alimentos excepcionales y que se guarden reservas de alimentos para estas celebraciones. De este modo estas ceremonias son importantísimos momentos para el reforzamiento de la cohesión y agregación social (Wolf 1975: 16-17, Sahlins 1983: 241, Berrocal 2004).

Los banquetes se celebraban no solo en las asambleas sino en otros momentos y en otros espacios. En el área galaica, en el interior de varios castros y oppida, se han identificado recintos que habrían servido como "santuarios urbanos". En el caso del Castro de Monte Mozinho (Oldrões-Galegos, Penafiel, Portugal) se han identificado restos que indican que en el espacio ritual se celebraron banquetes colectivos (González 2007b: 551-553, 567-570, Torres-Martínez 2011a: 475-479). Uno de los mejores ejemplos de este tipo de práctica es el del "altar" en el Castro de Capote (Higuera la Real, Badajoz) donde se documentan los restos de un gran banquete ritual en un espacio construido para este tipo de práctica (Berrocal 1992: 199-201, 1994, 2004, Almagro y Berrocal 1997: 579-585).

Dentro de la estructura vecinal conviven, estrecha e inseparablemente unidas y complementarias, dos tipos de relación entre los habitantes de los distintos territorios: las gentilicias y la estructura vecinal. Las primeras se establecen a través de la pertenencia a la familia o a la parentela (consanguineidad real o "simbólica"), organizada a partir del sexo y ordenada por grupos de edad, y con su propio sistema de reciprocidad. Ambas estructuras forman el ámbito de relación social y político de estas sociedades que, estructuradas en lo que los autores grecolatinos denominan pagus y civitates/populi, forman las ethne/nationes. Este modelo, desarrollado para las sociedades de la Edad del Hierro del norte de la península ibérica, resulta equivalente al que otros autores aceptan para otras sociedades del ámbito céltico del occidente de Europa (Fichtl 2004: 121-124, Verger 2009: 62-66, Torres-Martínez 2011a: 358-364, Fernández 2011a: 11-14).

Estas sociedades son segmentarias, están muy jerarquizadas (familiar y vecinalmente) y resulta evidente, en muchos casos, que existen importantes desigualdades sociales. Este tipo de contradicciones aparentes, en sistemas de equilibrio precario, son propias de cualquier sociedad humana. Ya hemos explicado que los mecanismos de reciprocidad buscan establecer una relativa "igualdad de oportunidades" entre todos los integrantes de la sociedad. Pero esto no hace iguales a todas las partes y determinados individuos, familias o linajes logran acumular influencia, recursos (humanos, económicos) y relaciones: poder; lo que les sitúa en la cúspide social.

No obstante, en este tipo de sociedades estas situaciones suelen ser temporales e incluso transitorias y el relevo de las figuras carismáticas en las estructuras de poder es continuo, probablemente porque las cualidades personales, el talento y el carisma (dentro de ese determinado sistema de valores) o el favor y admiración de los demás recaían sucesivamente en distintos individuos y grupos familiares. Además, el poder conseguido establece una deuda de servicio con aquellos que lo han hecho posible y la preeminencia alcanzada nunca parece conseguir el consenso absoluto. C.J. César B.G. (VI, 11-2-5) explica la situación de la Galia, probablemente extrapolable en gran medida a una gran parte del ámbito céltico de Europa occidental:

En la Galia hay bandos, no sólo en todos los pueblos, distritos y comarcas, sino incluso, casi dentro de cada familia, y son líderes de estas facciones los que se considera que, a su entender, tiene más prestigio: todos los asuntos y decisiones se someten a su arbitrio y dictamen. Y esta costumbre parece existir desde antiguo con el propósito de que nadie de entre el pueblo se encuentre indefenso frente a un potentado, pues ninguno tolera que se avasalle o acorrale a los suyos y, si no procede así, pierde toda autoridad entre ellos (Caerols 2006: 209-210).

En este ámbito de relación es muy importante el prestigio y, dentro de este tipo de sistemas, la reciprocidad y el equilibrio resultan fundamentales en todos los ámbitos de relación como hemos visto anteriormente (Verger 2009: 62-74, Fernández 2011a: 14, 17-20). 


\subsection{La guerra y la violencia: las relaciones con los otros}

En el panorama descrito, en el que la premisa de relación se establece en la tendencia hacia la solidaridad y reciprocidad, también caben las relaciones que excluyen radicalmente estas prácticas. Esto es debido a que la reciprocidad construye sociedades integrando a los que pertenecen a estas pero estableciendo, del mismo modo, a los que quedan fuera. Son los otros, los que no pertenecen al grupo, los que no comparten una sangre y unos antepasados comunes. Es con estos otros grupos con los que se llega a competir y, en ocasiones, a luchar. Cuando el recurso a la violencia con otros grupos humanos se convierte en frecuente, cambian los valores de los grupos. M. Sahlins enuncia cómo, en muchas culturas primitivas, los sistemas morales y los valores se convierten en algo relativo, situacional, en las relaciones con los otros «Un acto determinado no es bueno ni malo por sí mismo, depende de quien sea "el otro"» (Sahlins 1983: 218). Cuando el enfrentamiento violento y la guerra se convierten en una forma habitual de relación con otros grupos se producen profundos cambios en la estructura ideológica del grupo (Gracia 2003: 40, 2006).

En la Edad del Hierro, en el ámbito céltico, las sociedades agro-ganaderas y de tendencia segmentaria han desarrollado una intensa cultura guerrera, hecho que no se puede negar por las evidencias a este respecto (James 2007, Karl 2009: 137). Esto no quiere decir que las sociedades estén continuamente haciéndose la guerra de modo indiscriminado y sin ningún control, todo lo contrario. Es precisamente en las culturas de carácter guerrero en las que el uso de la violencia está perfectamente reglado y ritualizado tanto en los choques ocasionales como en los conflictos de baja intensidad o en los grandes enfrentamientos. No son sociedades de "fanfarrones" violentos. En realidad, en este tipo de sociedades, la guerra se convierte en parte intrínseca de todo el sistema cultural y posee estrictos sistemas de regulación ética y moral sancionados por las creencias religiosas (Sopeña 1995: 75-80, Almagro 2002: 64, Brunaux 2004: 37-40).

Como ya hemos mencionado, la guerra refuerza los mecanismos de reciprocidad entre los miembros de una sociedad, entre los que luchan juntos o los que son aliados. La guerra intensifica la interacción social y la solidaridad de un modo incluso extremo ya que, en muchas ocasiones, es la supervivencia de un grupo lo que está en juego (Sahlins 1983: 218, 234-235). Esto establece, al menos a grandes rasgos, lo que es legítimo e ilegítimo y también lo que se espera del enemigo: su comportamiento ha de ser contestado en reciprocidad. Hay unas formas establecidas de hacer la guerra que están inmersas en las necesidades de un mundo agropecuario y eso se puede percibir en los relatos de los autores grecolatinos. La sensación de inseguridad no vendría tanto de la guerra como de la ruptura de estas normas, lo que entre los pueblos célticos sería más bien excepcional. No ocurre lo mismo cuando surge el enfrentamiento con culturas distantes que introducen nuevas normas (o la ausencia de estas, el desorden) como las del ámbito grecolatino (Ciprés 1993, 2002, Sánchez 2001, 2002, 2003, 2006, Gracia 2006; Torres-Martínez 2011a: 386-407, 433-441).

\section{FORMAS DE RECIPROCIDAD "NEGATIVAS". LA HOSPITALIDAD Y LA RECIPROCIDAD CON LOS DIOSES Y LOS SERES DEL MÁS ALLÁ}

\subsection{Hospitalidad}

La hospitalidad, el mecanismo de reciprocidad diferida más impersonal, tiene su pleno sentido precisamente en este contexto cultural. Es esta una de las formas más interesantes de reciprocidad ya que se realiza sin que exista un beneficio evidente y directo de esta práctica. Consiste en la solidaridad indiscriminada con los extraños, los forasteros y los viajeros. Aunque entraría dentro de lo que se considera reciprocidad negativa, no podemos definirla como tal, sino más bien como positiva. En la hospitalidad se presta un servicio y una serie de productos asociados como son el hospedaje, la alimentación, la asistencia y la protección a cambio de la esperanza de poder recibir el mismo trato de quien sea necesario en el momento en que sea necesario. Es, por tanto, un mecanismo del que todos esperan beneficiarse, en algún momento, si llega a ser preciso. Por tanto, se practica de modo indiscriminado. Además, tiene un componente sacro y la negación o la ruptura de la hospitalidad lleva consigo un castigo divino (Torres-Martínez 2011b: 41-42).

Por los autores grecolatinos sabemos que en la Antigüedad existía la creencia de que los dioses protegían a los viajeros y favorecían a aquellos que los hospedaban y trataban con generosidad. Era un sistema de reciprocidad generalizado en todo el Mundo Antiguo conocido y en ámbitos geográficos tan amplios que merece un estudio específico. Atender al que lo necesitaba, fuera cual fuera su condición, era considerado 
como una obligación sagrada (Sopeña 1995: 128, García 1999: 141-142).

Diodoro Sículo $(\mathrm{V}, 34,1)$, entre sus descripciones de los distintos pueblos que habitan Iberia, refiere de los celtíberos (que explica estaban emparentados con los galos) que su hospitalidad era una de sus características más destacadas:

Los celtíberos son crueles en sus costumbres hacia los malhechores y enemigos, pero honorables y bondadosos y cercanos a los hombres. Cuando por ejemplo algún extranjero estaba entre ellos todos lo invitaban a detenerse en sus casas y rivalizaban entre sí en hospitalidad, y se habla con aprobación y se considera amado de los dioses a cualquiera de ellos que sea hospitalario con los extranjeros (Peralta 2003: 141).

Un comportamiento similar describe también Diodoro Sículo $(\mathrm{V}, 28)$ para los galos, por lo que hay elementos para atribuir este tipo de comportamiento a los pueblos célticos del occidente de Europa (Sopeña 1995: 128).

Parece que cuanto más feroz parece ser el carácter de un pueblo, más intensa es la práctica de la hospitalidad. Esto es lo que recoge C. J. César $B G$ (VI, 23), cuando explica la práctica de la hospitalidad entre los germanos: «Piensan que no es lícito violentar a un huésped. A quienes han acudido a ellos por cualquier asunto los protegen de todo atropello y los consideran sagrados, les abren las casas de todos y comparten con ellos su comida» (Caerols 2006: 218).

Tácito en su Germania (XXI, 2-3) explica también cómo practican la hospitalidad los germanos en un texto que, por su interés, reproducimos íntegramente ya que refleja bien el sentido de la reciprocidad en este ámbito cultural:

\footnotetext{
Ningún otro pueblo se entrega más efusivamente a los convites y a la hospitalidad. No dar cobijo a cualquier persona se tiene por sacrilegio; se le invita a compartir la mesa, preparada según los recursos de cada uno. Cuando éstos se acaban el que lo ha acogido le indica otra casa y lo acompaña. Sin ser invitados entran en la casa vecina. No importa, se les recibe con igual afabilidad. En lo que atañe al derecho de hospitalidad nadie hace distinción entre conocido y desconocido. Si el huésped pide alguna cosa cuando se marcha, es costumbre concedérsela; y existe también la posibilidad de pedirle a su vez algo. Gustan de los regalos, pero no llevan cuenta de lo que dan ni se ven obligados por lo que reciben (Alarcón 1999: 219-220).
}

El acogimiento en la propia casa y compartir la comida aparecen siempre como elementos esenciales de la hospitalidad. Y es que uno de los mecanismos básicos de la solidaridad y la reciprocidad es la comensalidad.

Las costumbres, las leyes de los distintos pueblos y las leyes divinas protegían a los viajeros en sus desplazamientos. E. Peralta hace referencia a un texto de Nicolás Damasceno en la que se explica que los celtas castigaban con la muerte a quien asesinaba un extranjero, mientras que la muerte de un conciudadano se castigaba con el exilio, lo que da cuenta de lo grave que era considerado ese tipo de crimen (Peralta 2003: 141). Esto es posible debido a que este era un mundo sin moneda y sin establecimientos para el hospedaje, los desplazamientos a medias y largas distancias, más allá del ámbito de parientes y compatriotas, solo resultaban posibles con la aceptación multilateral de este tipo de comportamiento por parte de todos los grupos hasta convertirse en costumbre (la norma no escrita aceptada por consenso) sancionada por los dioses (lo que la divinidad desea que los hombres hagan).

En este ámbito se encuentran los denominados pactos de hospitalidad, de los que son expresión las téseras de hospitalidad. Estos objetos son la expresión institucionalizada de esta práctica en una relación entre dos partes. Dicho pacto se desarrollaba normalmente entre dos familias, o bien una familia y una comunidad o bien dos comunidades, en algunos casos entre los representantes (cabeza de familia o similar) de los grupos y, probablemente también, entre los descendientes de los integrantes del pacto. La finalidad del acuerdo permitía a la persona que portaba la tésera y a sus asociados recibir la hospitalidad de la familia o del colectivo con el que existía dicho pacto. De este modo, estas personas estaban protegidas por la familia o grupo que las recibía como si fueran parte integrante de este, pasando a tener derechos y obligaciones similares. Pero aún no sabemos lo suficiente de estos pactos como para establecer sus contenidos (TorresMartínez 2011b: 39-41).

\subsection{Reciprocidad con los dioses y los seres del Más Allá}

Las relaciones de reciprocidad resultan también inseparables de la concepción religiosa y moral de las distintas culturas. En este sentido debemos llamar la atención sobre las formas de reciprocidad que los humanos intentan establecer con los dioses y seres espirituales mediantes ofrendas, regalos, etc. (dones) y también a través de la comensalidad simbolizada en el ritual del sacrificio y el banquete posterior. 
La reciprocidad con los dioses y seres inmateriales (antepasados, espíritus, divinidades o dioses) intenta integrar a estos dentro del sistema de relación familiar y social. Se agradece así a los dioses principalmente, y a sus agentes, que compartan sus recursos con los humanos. No obstante, al mismo tiempo se intenta integrarlos en redes de reciprocidad mediante los dones entregados y mediante el sacrificio y el banquete. Por tanto, el Don (el regalo u ofrenda) es también una inversión en un fondo infinito de dones (deudas morales y compromisos) entre las familias, los linajes y los distintos grupos humanos y sus dioses, seres divinos y antepasados. Es importante comprender que estas relaciones van mucho más allá del tiempo vital del individuo y comprenden en realidad a muchas generaciones en secuencias muy largas de tiempo. Los dones dados, aunque entregados como muestra de agradecimiento, también esperan una compensación, un reequilibrio. A través de ellos se intentan crear lazos eternos de amistad y reciprocidad con el Más Allá (Mauss 1971: 173, 178, 195, 199-200, 202, 222, van Gennep 1986: 39-40, Pérez 1991: 172, Torres-Martínez 2011a: 482-483).

Los sacrificios son una parte esencial de los rituales religiosos en toda la Antigüedad y también de muchas de las culturas que denominamos de tecnologías simples. El sacrificio es el más importante elemento ritual en la religiosidad céltica y el acto central de la asamblea en lo que se refiere a su dimensión religiosa por varios motivos: en primer lugar, es un acto de comunicación entre los humanos y la divinidad; en segundo término, el animal sacrificado es una ofrenda para obsequiar a la divinidad o para compartir con esta; y, por último, a través de él se establece la comensalidad (reciprocidad) entre humanos y divinidad. Este esquema intenta establecer una relación de reciprocidad de modo similar a como ocurre entre parientes, amigos y vecinos, entre huéspedes y hospedados o hacia una persona a la que se desea agasajar. En este sentido, resulta también, por tanto, un acto de relación social.

De la misma manera, los banquetes funerarios (rituales de conmemoración de los difuntos y antepasados comunes) se convierten también en una forma de agregación social. Sirven para mantener y renovar los lazos de parentesco, vecindad y reciprocidad social entre los vivos y los muertos, y también especialmente entre los vivos que los conmemoran (van Gennep 1986: 39-40, 158-169, Sopeña 1987: 141-147, Pérez 1991: 172-173, Berrocal-Rangel 2004, Torres-Martínez 2011a: 482-487).

\section{CONCLUSIONES}

Este trabajo no pretende ser más que una llamada de atención sobre lo que consideramos es uno de los fenómenos culturales más importantes de los que atañen a las relaciones sociales en la Protohistoria: la reciprocidad. Esta práctica forma parte de las relaciones de solidaridad que los humanos establecen entre sí para construir las sociedades. Sirven para establecer lazos y redes de intercambios entre las personas, las familias y los grupos, que poseen tendencias igualitarias y horizontales, convirtiéndose en elementos de regulación social. Este tipo de relaciones son principalmente económicas, más cualitativas que cuantitativas, y eminentemente morales. Requieren de la búsqueda de un continuo equilibrio en las relaciones y están sujetas a una fuerte ritualización. Sin embargo, no establecen sociedades igualitarias sino relaciones de tendencia igualitaria.

En el ámbito cultural céltico, en sociedades campesinas agro-ganaderas, de cultura guerrera y tendencia segmentaria, las relaciones de reciprocidad sirven para comprender los procesos de construcción de las redes de relaciones sociales desde la esfera familiar y la vecinal hasta las civitates/populi y las ethne/nationes. También sirven para explicar fenómenos como la hospitalidad o para poder enfocar, desde un punto de vista diferente, las prácticas rituales (como elementos esenciales en las relaciones con los dioses) y su papel como elementos de agregación social.

\section{Agradecimientos}

Este trabajo se ha realizado dentro del marco del proyecto de investigación Forma Hispaniae Prerromanae Ref. HAR2010 (Subprograma HIST) desarrollado en el Departamento de Prehistoria de la Universidad Complutense de Madrid. El autor presta sus servicios en dicho proyecto como investigador contratado.

\section{BIBLIOGRAFÍA}

Alberro, M. (2006): "La Feria-Fiesta-Asamblea Óenach de Irlanda y sus posibles paralelos en la antigua Irlanda Céltica". Habis 37: 159-182.

Almagro Gorbea, M (2002): "Urbanismo y sociedad en la Hispania Húmeda", en M.A. de Blas y A. Villa (eds.), Los poblados fortificados del noroeste de la Península Ibérica: Formación y desarrollo de la Cultura Castreña: 47-79. Navia, Ayuntamiento del Navia. 
Almagro Gorbea, M. y Berrocal Rangel, L. (1997): “Entre íberos y celtas: sobre santuarios comunales urbanos y rituales gentilicios en Hispania". Quaderns de Prehistòria i Arqueología de Castelló 18: 567-588.

Alarcón Martínez, B. (1999): P.C. Tácito, Vida de Julio Agrícola. Germania. Diálogo de los oradores. Madrid, Akal.

Álvarez-Sanchís, J. R. (1993): "Los Castros de Ávila", en M. Almagro y G. Ruiz (ed.), Los celtas: Hispania y Europa. Actas del Curso de Verano de 1992: 255-284. Madrid, Actas.

Braudel, F. (2002): Las ambiciones de la Historia. Barcelona, Crítica.

Berrocal Rangel, L. (1992): Los pueblos célticos del suroeste de la Península Ibérica. Complutum Extra (2). Madrid, Universidad Complutense.

Berrocal Rangel, L. (1994): El altar prerromano del Castrejón del Capote: ensayo etno-arqueológico de un ritual céltico en el suroeste Peninsular. Excavaciones Arqueológicas en Capote (Beturia Céltica), vol. 2. Madrid, Universidad Autónoma de Madrid.

Berrocal Rangel, L. (2004): "Banquetes y rituales colectivos en el suroeste Peninsular". Cuadernos de Prehistoria y Arqueología 30: 105-120.

Brunaux, J.L. (2004): Guerre et religión en Gaule. Essai d'anthropologie celtique. París, Errance.

Cabal, C. (1992): Las Tradiciones Populares Asturianas II. La Familia la Vivienda y Oficios Primitivos (1931). Oviedo, Anaquel Cultural Asturiano.

Caerols, J. J. (2006): C. J. César, Comentarios a la Guerra de las Galias. Madrid, Alianza.

Chic García, G. (2009): El Comercio y el Mediterráneo en la Antigüedad Clásica. Serie Interdisciplinar. Madrid, Akal Universitaria.

Ciprés Torres, P. (1993): Guerra y sociedad en la Hispania indoeuropea. Anejos de Veleia. Serie Minor 3. Vitoria, Universidad del País Vasco.

Ciprés Torres, P. (2002): "Instituciones militares indoeuropeas en la Península Ibérica", en P. Moret y F. Quesada (eds.), La guerra en el mundo ibérico y celtibérico (ss. VI a. de C.): 135-152. Madrid, Casa de Velázquez.

Coldstream, J. N. (1983): "Gift Exchange in the eigthth century B.C.”, en R. Hägg (ed.), The Greek Renaissance of the Eighth Century B. C.: Tradition and Innovation: 201-207. Estocolmo, Svenska Institutet I Athen.

Durkheim, E. (2005): Las reglas del método sociológico. Madrid, Biblioteca Nueva.

Dyson-Hudson, R. y Alden Smith, E. (1983): "Territorialidad humana: una reconsideración ecológica", en M.J. Buxó (ed.), Cultura y Ecología en las Sociedades Primitivas: 151-185. Barcelona, Temas de Antropología.

Espina, A. (2005): "Darwinismo social: de Spencer a Bagehot". Reis 110: 175-187.

Fernández Benítez, V., Fernández García, J.A., Fernández García, X.; García Martínez, A., López Álvarez, J. Martínez Lorenzo, L., Muñoz Fuente, J. A., Prieto Vergara, M. A., Rodríguez Rodríguez, R., Suarez López, J. Suarez Rodríguez, M. y Villa Gutierrez, J. (2002): Trabajar para comer. Producción $y$ alimentación en la Asturies tradicional. Gijón, Documentación General.

Fernández Götz, M.A. (2011a): "Niveles sociopolíticos y órganos de gobierno en la Galia de finales de la Protohistoria". Habis 42: 7-26.

Fernández Götz, M.A. (2011b): “Cultos, ferias y asambleas: los santuarios protohistóricos del Rin MedioMosela como espacios de agregación". Palaeohispanica 11: 127-154.

Fichtl, S. (2004): Les peuples gaulois. IIIe-Ier siècles av. J.-C. París, Errance.

Fichtl, S. (2005): La Ville Celtique. Les oppida de 150 av. J.-C.à 15 ap. J.-C. Deuxième édition revue et augmentée. París, Errance.

Finley, M. I. (1999): El Mundo de Odiseo. Madrid, Fondo de Cultura Económica.

García Quintela, M. V. (1999): Mitología y mitos de la Hispania Prerromana, III. Torrejón de Ardoz, Akal Universitaria.

García Quintela, M. V., Criado Boado, F., González García, F. J., Parcero Oubiña, C. y Santos Estévez, M. (2003): "Souveraineté et sanctuaires dans l'Espagne celtique. Études Comparées D'Historie et D'Archéologie". Memoires de la Societé Belge d'Études Celtiques 17: 75-90.

Giobellina Brumana, F. (2010): "El don del ensayo" en F. Giobellina (Ed.), Ensayo sobre los Dones. Forma y función del intercambio en las Sociedades Arcaicas: 7-60. Buenos Aires, Katz.

Godelier, M. (1999): The enigma of the gift. Cambridge, Polity Press \& Blackwell Publishers.

Goleman, D. (2010a): Inteligencia Social. La nueva ciencia de las relaciones humanas. Barcelona, Kairós.

Goleman, D. (2010b): Inteligencia Emocional. Barcelona, Kairós.

Gómez Espelosín, F. J. (2007): Estrabón. Geografía de Iberia. Madrid, Alianza.

González Ruibal, A. (2007): Galaicos. Poder y comunidad en el noroeste de la Península Ibérica 
(1200 a. C.-50 d.C.). Tomo I y II. La Coruña, Museu Arqueolóxico e Histórico da Coruña.

Gracia Alonso, F. (2003): La guerra en la Protohistoria. Héroes, nobles, mercenarios y campesinos. Barcelona, Ariel.

Gracia Alonso, F. (2006): “¡Ay de los vencidos! Las consecuencias de la guerra protohistórica en la Península Ibérica". Cypsela 16: 65-86.

Herman, G. (1987): Ritualised friendship and the greek city. Cambridge, Cambridge University Press.

Hernando Gonzalo, A. (2002): Arqueología de la Identidad. Madrid, Akal.

James, S. (2007): "A bloodless past the pacification of Early Iron Age Britain", en C. Hasselgrove y R. Pope (eds.), The Early Iron Age in Britain and the near continent: 160-173. Oxford, Routledge.

Karl, R. (2009): "The court of law in Iron Age Societies", en R. Karl y J. Leskovar (eds.), Interpretierte Eisenzeiten 3. Fallstudien, Methoden, Theorie. Tagungsbeiträge der 3. Linzer Gespräche zur interpretativen Eisenzeitarchäologie. Studien zur Kulturgeschichte von Oberösterreich Folge 22: 135-60. Linz, Oberösterreichisches Landesmuseum.

Lewontin, R. C., Rose, S. y Kamin, L.J. (1996): No está en los genes. Crítica del racismo biológico. Barcelona, Grijalbo Mondadori.

Marco Simón, F. (1993): "La religiosidad en la Céltíca hispana”, en M. Almagro y G. Ruiz (eds.), Los celtas: Hispania y Europa. Actas del Curso de Verano de 1992: 477-512. Madrid, Actas.

Mauss, M. (1971): "Ensayo sobre los Dones. Razón y forma del cambio en las Sociedades Primitivas", en M. Mauss (recopilación), Sociología y Antropología: 153-263. Madrid, Tecnos.

Mauss, M. (2010): Ensayo sobre los Dones. Forma y función del intercambio en las Sociedades Arcaicas. Edición de F. Giobellina Brimana. Buenos Aires, Katz.

Montes Miralles, M.Y. (2006a): Ideología aristocrática en los orígenes del arcaísmo griego. Estrategias de alteridad en la Ilíada. BAR International Series 1487. Oxford, John \& Erica Hedges Ltd.

Montes Miralles, M.Y. (2006b): "El miedo al desorden: estrategias de recuperación del equilibrio social en el mito iliádico". Gerión 24(1): 119-141.

Moreno Feliu, P. (2011): El bosque de las gracias y sus pasatiempos. Madrid, Trotta.

Osteed, M. (2002): The question of the gift. Essays across disciplines. Londres-Nueva York, Routledge.

Peralta Labrador, E. (2003): Los Cántabros antes de Roma (2 $\left.{ }^{\mathrm{a}} \mathrm{Ed}\right)$. Bibliotheca Archaeologica Hispana, vol. 5. Madrid, Real Academia de la Historia.
Pérez Vilatela, L. (1991): "El especialista religioso entre celtíberos, lusitanos y vascones (estado de la cuestión y perspectivas)", en S. Castillo (coord.), La Historia Social en España. Actualidad y Perspectivas. Actas del I Congreso de la Asociación de Historia Social: 165-177. Madrid, Siglo XXI.

Peyre, Ch. (1996): "Prologue", en L.P. Delestrée, Monnayages et Peuples gaulois du Nord-Ouest: 5-8. París, Maison Florange-Claude Burgan.

Polanyi, K. (1987): La gran transformación. Madrid, La Piqueta.

Ruiz Zapatero, G. y Álvarez Sanchís, J. (1999): "Ulaca, la Pompeya Vetona”. Revista de Arqueología 216: 36-47.

Sánchez Moreno, E. (2001): “Algunas notas sobre la guerra como estrategia de interacción social en la Hispania prerromana: Viriato, jefe redistributivo (I)". Habis 32: 149-169.

Sánchez Moreno, E. (2002): “Algunas notas sobre la guerra como estrategia de interacción social en la Hispania prerromana: Viriato, jefe redistributivo (II)". Habis 33: 169-202.

Sánchez Moreno, E. (2003): “El botín de Viriato: guerra y sociedad en Lusitania". Boletín de la Asociación Española de Arqueología 42: 305-331.

Sánchez Moreno, E. (2006): "Ex pastore latro, ex latrone dux... Medioambiente, guerra y poder en el occidente de Iberia", en T. Ñaco y I. Arrayás (eds.), War and Territory in the Roman World: 55-79. Oxford, John \& Erica Hedges Ltd.

Sandin, M. (2000): "Sobre una redundancia: el Darwinismo Social”. Asclepio LII(2): 27-50.

San Miguel Maté, L. C. (1995): "Civitas y secundarización de la producción, ¿Las dos claves de interpretación del poblamiento vacceo?", en F. Burillo (ed.), III Simposio sobre Los Celtiberos, Poblamiento Celtibérico: 373-380. Zaragoza, Institución Fernando el Católico.

Sahlins, M. (1983): Economía de la Edad de Piedra. Torrejón de Ardoz, Akal.

Sopeña Genzor, G. (1987): Dioses, Ética, Ritos. Aproximaciones para una comprensión de la religiosidad entre los pueblos celtibéricos. Zaragoza, Prensas Universitarias de Zaragoza.

Sopeña Genzor, G. (1995): Ética y Ritual. Aproximación al estudio de la religiosidad de los pueblos celtibéricos. Zaragoza, Institución Fernando el Católico.

Sykes, K. (2005): Arguing with anthropology: an introduction to critical theories of the gift. New York, Routledge. 
Torres Martínez, J.F.K. (2003): La Economía de los Celtas de la Hispania Atlántica. Vol. I Agricultura, ganadería y recursos naturales. Coruña, Toxosoutos.

Torres Martínez, J.F.K. (2005): La Economía de los Celtas de la Hispania Atlántica. Vol. II. Economía, territorio y Sociedad. Coruña, Toxosoutos.

Torres Martínez, J.F.K. (2010): “El Medio ambiente antiguo, la construcción del territorio y la obtención de recursos en la Edad del Hierro de Cantabria", en A. Serna, A. Martínez, A. y Fernández, V. (coords.), Castros y Castra en Cantabria. (Fortificaciones desde los orígenes de la Edad del Hierro a las guerras con Roma). Catálogo, revisión y puesta al día: 74-109. Santander, Acanto.

Torres Martínez, J.F.K. (2011a): El Cantábrico en la Edad del Hierro. Medioambiente, Economía, Territorio y Sociedad. Madrid, Real Academia de la Historia.

Torres Martínez, J.F.K. (2011b): “Una posible tésera d'hospitalidá afayada n'Asturies. Les rellaciones d'agospiu na Edá del fierro ente los ástures y otros puelos célticos". Asturies 31: 34-42.

Valdés, L. (2006): "El santuario protohistórico de Gastiburu (siglos IV al I a.C.) y el calendario estacional
(Arratzu, Bizkaia)". Munibe (Antropología, Arqueología) 57(2): 333-343.

Valdés, L. (2009a): Gastiburu. El santuario vasco de la Edad del Hierro. Vol. I, Texto. Madrid, Real Academia de la Historia.

Valdés, L. (2009b): Gastiburu. El santuario vasco de la Edad del Hierro. Vol. II, Imágenes. Madrid, Real Academia de la Historia.

Valdés, L. y Pujana, I (2003): “El santuario protohistórico de Gastiburu y el calendario estacional (siglos IV al I a.C.)". Bolskan 19: 249-254.

Valdés del Toro, R. y Lorenzi Fernández, E. (2004): ¿Bótoche unha mao? La evolución de las relaciones de reciprocidad campesinas en Tapia de Casariego (Asturias) (1960-2000). Gijón, Museo del Pueblo de Asturias.

Van Gennep, A. (1986): Los ritos de paso. Madrid, Taurus.

Van Wees, H. (1992): Status warriors. War, violence and society in Homer and History. Amsterdam, J.C. Gieben.

Verger, S. (2009): "Société, Politique et religion en Gaule avant la Conquête. Éléments pour une étude anthropologique". Pallas 80: 61-82.

Wolf, E. (1975): Los Campesinos. Barcelona, Labor. 